\title{
High-fidelity simulation: Making hard to teach cases teachable
}

\author{
Meghana R. K. Helder, MD, and John M. Stulak, MD
}

\author{
From the Department of Cardiovascular Surgery, Mayo Clinic, Rochester, Minn. \\ Disclosures: Authors have nothing to disclose with regard to commercial support. \\ Received for publication Oct 6, 2017; accepted for publication Oct 7, 2017; available ahead of print Oct 31, 2017. \\ Address for reprints: John M. Stulak, MD, Department of Cardiovascular Surgery, Mayo Clinic, St. Mary's Hos- \\ pital, Joseph 5-200, 1216 Second St SW, Rochester, MN 55902 (E-mail: stulak.john@mayo.edu). \\ J Thorac Cardiovasc Surg 2018;156:1137-8 \\ $0022-5223 / \$ 36.00$ \\ Copyright (c) 2017 by The American Association for Thoracic Surgery \\ https://doi.org/10.1016/j.jtcvs.2017.10.024
}

Hermsen and colleagues ${ }^{1}$ describe the development of a 3-dimensional (3D) printing-based simulation to teach septal myectomy. The anatomy of 5 separate patients were used to create models, and these models were used for assessment of the residents. Didactic materials were the only instruction for model 1 , but some technical feedback was given for the rest of the models. Residents were videotaped during their resection and given scores by the faculty. One faculty member was also videotaped doing the myectomies. Residents improved in total volume resected through the 5 models. There was poor agreement between faculty assessments, and faculty assessment scores did not identify the videotapes of faculty performing the myectomy.

The authors should be congratulated for developing a 3Dprinted model that could be used for myectomy. Septal myectomy, as the authors point out, is a hard operation to teach in the operating room for a myriad of reasons, including limited visibility to the assistant, small margin for error leading to major complications, and small number of operations performed at most institutions, which does not allow residents enough repetition to master the operation. Even at our institution, we recognize the potential that $3 \mathrm{D}$ printing holds for deliberate practice and simulation. ${ }^{2}$ The authors are at the leading cusp of what can be achieved with surgical education using $3 \mathrm{D}$ printing, and we would encourage them to strive further.

There are several important considerations to evaluate when embracing this novel approach to education. First to address simulation curricula, this study and a number of recently published studies ${ }^{3,4}$ seem to focus more on assessment than teaching. This is possibly secondary to limited time of faculty. However, the clinical experience of an experienced surgeon is critical to refine the deliberate practice that is meant to result from surgical simulation, especially if feedback is returned in a relaxed, calm setting. If surgeons cannot be present during the simulation, an alternative could be providing videotapes of faculty simulation so that residents have something to compare their deliberate practice with.

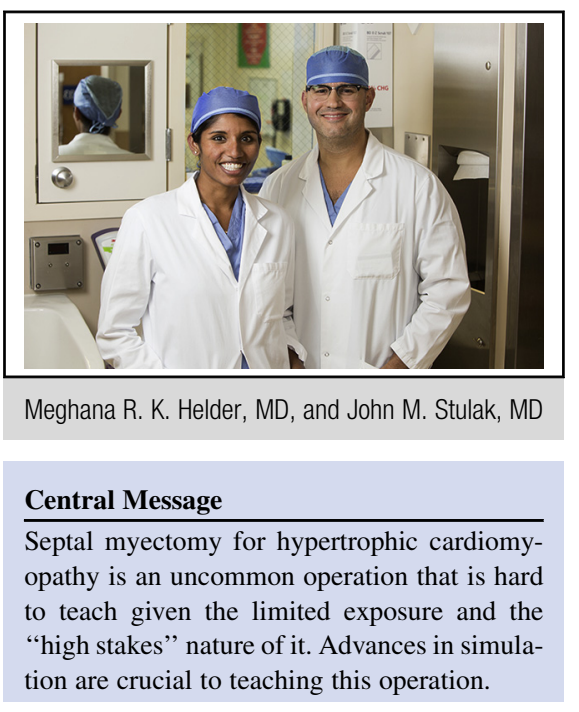

See Article page 1139.

Second, the ability to create and fix complications from operations must be a priority of any simulation curricula. The current model in this study is not equipped to simulate need for ventricular septal defect repair if one were to be created. Future directions of 3D printed models should include this, even if it means a higher cost.

Third, given that one of the hardest things about a septal myectomy is the limited exposure, this should be better represented in the model. The described 3D printed model ends at the sinotubular junction. Additional printing and the creation of an ascending aorta would enable residents to make an aortotomy and experience the exposure of the operation with a higher level of fidelity. Most residents can perform an operation if exposure is created for them; however, the transition to setting up the operation in addition to completion of the critical portion of the procedure is the ultimate goal.

The authors have created high-fidelity simulation curricula to teach septal myectomy. However, future directions should focus on incorporating timely feedback to allow for better practice, to enable the ability to create and repair complications, and to maximize the ability for residents to set up exposure.

\section{References}

1. Hermsen JL, Yang R, Burke TM, Dardas T, Jacobs LM, Verrier ED, et al. Development of a $3 \mathrm{D}$ printing based cardiac surgical simulation 
curriculum to teach septal myectomy. J Thorac Cardiovasc Surg. 2018; 156:1139-48.e3.

2. Dearani JA, Gold M, Leibovich BC, Ericsson KA, Khabbaz KR, Foley TA, et al. The role of imaging, deliberate practice, structure, and improvisation in approaching surgical perfection. J Thorac Cardiovasc Surg. 2017;154: 1329-36.
3. Mokadam NA, Fann JI, Hicks GL, Nesbitt JC, Burkhart HM, Conte JV, et al. Experience with the cardiac surgery simulation curriculum: results of the resident and faculty survey. Ann Thorac Surg. 2017;103:322-8.

4. Fann JI, Caffarelli AD, Georgette G, Howard SK, Gaba DM, Youngblood P, et al. Improvement in coronary anastomosis with cardiac surgery simulation. J Thorac Cardiovasc Surg. 2008;136:1486-91. 